\title{
POP UP THE EPHEMERALITY LOOKING FOR ITS DESIGN
}

\author{
José Silveira Dias ${ }^{1}$, Dulce Loução ${ }^{2}$ \\ ${ }^{1}$ CIAUD Researcher, School of Architecture, University of Lisbon, silveiradias@gmail.com \\ 2 Prof. Dr., School of Architecture, University of Lisbon, PORTUGAL, dulce.loucao@gmail.com
}

\begin{abstract}
Since the 1990s, we have been witnessing a joint global change in society, economics, politics and culture. From the acceleration of these changes and erosion that causes its perception, it can be deduced an urgent and present need of society to seek ethical and moral values.

The research contributes to knowledge when it holds a significant problem, which challenges the intellect with visionary, entrepreneurial and sustainable strategy, seeking a greater result through a scientific approach that seeks the unity of knowledge.

As an abstract concept of event, the Pop Up can be defined as a body in constant motion and adaptable to the place, responsible for the vital regulation of the being. As research legitimizes the abstraction, the virtues of Pop Up - transgression, contamination, portability, revelation, mishap and ploy - qualify it as a model in the dynamics of consumption, culture and art, contributing to sociocultural homeostasis.

The Pop Up lacks investigation that integrates its assumption as a concept for retail strategies, culture and art. Its ephemerality - revelation and concealment - may also contribute to Sustainable Design. It is intended to guide the practice of architecture and design, optimizing the knowledge in abstraction for the development of theories and methods, through transdisciplinary studies, seeking to encourage a new understanding of reality, articulating elements that pass between, over and across disciplines to understand complexity.
\end{abstract}

Human beings, who react affectively to the event (Pop Up) and set it strategically, can contribute to sociocultural homeostasis, recognizing who we are presently and concerning ourselves with what we may be.

The Pop Up can contaminate design in the construction of an equilateral triangle whose vertices are the retail design, the exhibition design and the urban and conceptual art. This triangulation does not seem well documented for its definition, characterization and life cycle.

In retail design, Pop Up designates a category of temporary shops with event character, narrating a story and acting as a link between different events in space/time for an experiment and in identifiable areas other than the retail design.

In urban art, Pop Up, as a social practice, allows the appropriation of urban space, from graffiti to performance, involving social, political and cultural significance.

In conceptual art, Pop Up, as an idea, overlaps the execution of the work, and the process is more important than the hold object. It requires an overvaluation of reflective and experiential activity. It rejects the commercial aspect of consumption and tries to imbue its activity with social, ecological and intellectual values.

In a context of artistic exploration, the meeting of certain masterpieces and the absence of others from a museum, invites all of them to meet within the human spirit through imagination: the imaginary museum aims 
to add as much as possible to the incomplete collections of real museums. Through internet we have the most significant works and images able to expand our memory. The Pop Up also revises itself as an instrument that can expand the mental museum that stimulates creativity and imagination for knowledge.

By philosophy and poetic we reflect our condition of existence, and the Pop Up can be applied as a model to stimulate creativity.

The possibility of a place to stimulate creativity may involve the use of a non-place (Pop Up) which, in his own amazing action, can boost the affective state of the human being in relation to others and to objects on a design ambition.

The Pop Up, as hermeneutic perspective, can help to achieve balance in all aspects of our existence, pursuing perfection in other areas and beyond the tangible world of technology and consumption.

Keywords: Ephemerality, Pop Up, Architecture, Retail Design, Exhibit Design, Urban Art, Conceptual Art.

\section{POP UP}

In the transition from a society of the third industrial revolution to a knowledge and information society, the need and desire to learn, to know more and understand the world better is imposed. From a society of tangible assets, reminiscent of an essentially material goods economy and industrial capitalism, where the field of means of production dictated the development and wealth, we're now moving to a new kind of knowledge society: a society with the ambition to build their own understanding of the world, through recognition and interpretation of the phenomena, in a sustainable context. We are witnessing therefore a paradigm shift in which the values of immateriality emerge rather than physical assets, and this sense of change is essentially intangible.

The retail environment is always changing, it provides trends and anticipates changes in response to consumer aspirations, as well as retail spaces are contemporary and have constantly updated, being innovative, interactive and visionary. In store categories, the pop up store is distinguished from others by its dynamics in time and space. They are temporary stores that survive for a short period of time by transporting a brand. They have installation character and derive from guerrilla marketing - strategy that uses methods less conventional and more warlike actions. A pop up store can be mobile or simply settle in an unusual place without notice. It aims to be an unforgettable event and, almost always, in the middle of the crowd. This concept serves to raise the status of the brand and allows consumers access to exclusive products who only find them in this place, or provide consumers to participate in an interactive action without product. All creative strategies are apparently valid, provided that the intention of recognition by the brand, its customers and potential new customers (the sedimentation of the relationship of the first and in raising the relationship of seconds) are satisfied and at the same time can understand and define trends / products that will appear later in a more definitive shop, place to be announced. If we can recognize this category of store used in retail design, for its potential in the event of dynamic (cause / effect), cell (mobile / portable), stratagem (of mishap / manifest), it is believed that its assessment and validation can provide a model to be applied in other areas, in addition to retail. The virtues of pop up (transgression, contamination, portability, revelation, mishap, artifice) may consolidate pop up as a model of dynamics of consumption, culture and art.

Its ephemeral character (revelation and concealment) could help to find its plan. Its temporal / spatial event nature (pop up) can be responsible and promote responsibility (individual and collective), aiming to sustainable development, achieved by sociocultural homeostasis.

The conceptualization of pop up as ephemeral strategy in its validation as a model, can contribute to a more sustainable design (economy / equity / ecology), under the sociocultural homeostasis system, and in the following areas: the recovery of the sense of community and new economic and cultural dynamics in groups, tribes and associations; as driving the recovery and revitalization of the tangible and intangible heritage; in dialectic with the inside and the outside; the reinvention of the application of new and used materials and processing; the reinterpretation of the function and form of the products (ready-made), furniture, equipment, and devices (medium, display, sound and lighting); the promise, experience and respect in the environment (cognitive and emotional).

\section{IN RETAIL DESIGN}

The retail design as a method of analysis of processes and retail space strategies (inside and outside) is the discipline per excellence in the meaning of the brand design in all its touch points: name, logo, product, 
packaging, customer service, advertising, action and built and inbuilt environment. The pop up under the retail resign, begins as a possible name for a certain category of store (Mescher, 2010, p. 28). Generally, despite the brand, shops can acquire different categories: there are specific types (concept stores, flagship stores and lifestyle stores), depending on the places used for the promotion of a new concept or consolidation of a brand experience in the global market. This category of store happens in spaces for the retail masses, which converges the largest possible number of consumers and where investment will have higher return.

Currently, as the retail market presents itself saturated, with excess supply, marketing is constantly finding new ways to appeal to different markets. The online sale executed through virtual stores also became one of these mechanisms, although one can defend the need for a physical place in a way the experience to be more engaging. The senses have to validate the experience, to feel safe for consumption, and without consumer's confidence this experience is not realized with fluidity.

With cunning and treachery, Flusser (2010, pp. 09-10) compares the designer to "(...) a hidden conspirator extending their traps," (author's translation) and, as a horse of Troy, guerrilla marketing appropriated the pop up concept to achieve the effect of surprise and unexpected for the consumer. Hence, the consumer experience in a pop up store can be more intense than in a normal store. The expectations of not knowing exactly when the establishment will open again, the possibility, at each new opening, to meet different and unique products, living an exclusive experience that cannot be repeated, and the discovery of places outside the context of so-called traditional trade, confirm this wider scope of experience.

For entrepreneurs or brands, the priority of this type of business is not always profit, because the pop up stores can be a way to verify the acceptance of the product or service in the market, within an already consolidated consumption centre. It will be as a kind of test mode. Moreover, there are presumably advantages for those who are starting your business: the low cost of premises, equipment rental, licensing or leasing of space only for its period of use, and also the logistics eventually shared which can minimize the investment.

\section{IN EXHIBIT DESIGN}

However, the character of cunning, treachery, trespass, portability and manifest of the pop up, is identifiable in other areas beyond the retail design. At trade fairs, brand experiences, themed attractions, world exhibitions, galleries museums, interpretation centres, historic homes, and also in landscape art, urban and conceptual art, it is possible to identify an event in all these categories, beyond its exposure character (Locker, 2011, p.10).

The longevity of the pop up is variable as well as its scale. It can range from a simple table to a city area (world exhibitions), and can be real and/or virtual. Whether its commercial or cultural nature, pop up seems to be imperative communication and the narrative of a story (script), which acts as the link between these different events, in a three-dimensional space and in the integration of an experience.

The collaborations, supports and sponsorships between design, brands and institutions, in their interaction, create an approximation of synergy of art to their potential usurers. Through a complementary trusteeship, brands can sponsor major events as well as collaborate with artists, with a way to both promote them and also enhance the attraction of certain events and the proximity of the material and immaterial works. These events, to establish themselves temporarily in institutional buildings, create more audience for their collections, and visitors, in turn, feel greater leverage in relation to works of art, through the intimacy and belonging character that the facility gives them. The space is invaded by an isolated event, a temporary installation that becomes the focus of space. Associated with a unique character of communication, makes it possible for the visitor to experience the temporary facility, while the institution domicile and the brand that sponsors are known, providing a pretext to perform. All parts participate; they are individually valued and strengthen the intent of the whole that supports the art and technique.

\section{IN URBAN ART}

Urban art is an artistic practice intended for social impact. The works referred to as urban art permit the appropriation of urban space so diverse, from graffiti to the installation, through the performance. This form of communication involves in its manifestation a social, political and cultural significance of cities. As an expression in an urban context (public space) differs from the institutional character of events or business, as well as acts of vandalism.

It is believed that studying and analyzing the expression and significance of urban art, is to try to understand the city and the imagination of its inhabitants. Urban art references are enhanced by its qualitative dimension 
and ambiguity of its meaning. The strength of this significance comes at a public domain space, with bans, contradictions and conflicts inherent in the life of cities. In its implementation, reveals power relations between social groups, between groups and spaces, between interpretations of everyday life, memory and history of urban places. The place is a concrete manifestation of space, and the customs and habits build the image of this place (Bachelard, 1978, p. 186).

Because of its ephemeral and unusual character, urban art sets in privileged territory for its emergence in a provocative effect and/or sensory clash of denial, subversion or questioning of values. In this way, to reflect on urban art is to reflect on their lives in society, trying to understand the production process and the productivity of individuals in the symbolic universe and urban context. Above all, it is thought that we realize the urban culture, in how we relate to each other in the construction of otherness relationships, and also in humanizing the social, economic, political, religious, intellectual and artistic practices.

The urban art can revitalize a place, draw attention to the city's problems, for the vacant buildings, to the degraded and forgotten areas. The city is the place where people want to feel their welfare and their identity, also serving as an interface to express themselves. We understand that places become sterile when in the public space there is no longer space for interaction, communication, discussion, enrichment and dialogue. The urban art is as well a pretext and a possible intervention of people in public space. An urban intervention with this conceptual character that stands in the way of any inhabitant of the city, at the precise moment of this confrontation, can disrupt the normal rhythm of the day-to-day and stimulate individual reflection of the townspeople. Quickly, something that was forgotten at a much earlier layer of consciousness of each, pass it forward.

This stimulation of perception for such interventions leads us to choose urban art as support for the conceptual delimitation of pop up.

\section{IN CONCEPTUAL ART}

In conceptual art, the idea or concept overlaps the completion of the work and the process itself (notes, sketches, models, and reflections), which are more important than the held object, and can be exposed to show the origin and development of the idea from the beginning. The true work of art is the idea, because it emphasizes the ideation in the design of works, relegating importance to its material realization. Simultaneously to this implicit devaluation of manual activity, in the works of conceptual art both mental and sensory overvaluation reflective activity exists. Conceptual artists reject the commercial aspect of art consumption and at the same time try to imbue their activities with broader values such as social, ecological and intellectual issues, as opposed to the production of objects drawn second utilitarian and functional criteria, may contribute to the cultural institutionalization. The character of social scope of conceptual art requires greater involvement of the spectator, not only as to understand, but also in their participation. Thus, depending on the type of language, social or political approach, the form or the appropriate nature of this art, can follow very different lines of work, from body art, land art, process art, performance and art povera.

Recognition of conceptual art, including performance, is due above all to the fact that it raises critical questions about the meaning of art in everyday intensely mediated life (Goldberg, 2012, p. 290). It is also believed that this will be the instigator of a broader discussion about the size of global culture, and how art could generate empathy for numerous and diverse ways of life in a world expansion.

By analogy, the action of the pop up as conceptual model appropriates unexpectedly and involves people as artists, which react to provocation and tend to do part of the artistic work.

\section{TO CONTRIBUTE TO THE IMAGINARY MUSEUM}

The modern definition of museum dates back to the late eighteenth century, when private collections were available to the public. "The nineteenth century witnessed the museums; we still live them, and forget that imposed on the spectator a completely new relationship with the work of art." (Malraux, 2014, p. 09, author's translation). The museum creates an essential distance for contemplation and requires the spectator a new relationship with the artwork. The importance of the museum in the new interface is so great that we find it difficult to imagine it's not there forever, while the fact remains that museums are only a little over two centuries. The museum turns everything into a work of art, and thus contributes to the release of the function of each of the works it contains. If until the nineteenth century all works of art were the image of something, the museum suppressed the identity of these works and their models. The image of things is predominant. According to 
Malraux (2014, p. 10), the images are different from the things themselves and this specific difference is withdrawn their reason for being.

Referring to the artistic production, the concept of Malraux's metamorphosis assumes a gift look in relation to the work, putting it at odds with the works of the past, prior to its creation, and also with their contemporary works. This confrontation as an intellectual activity, present in western culture, is opposed to the abandonment of contemplation, reflecting a constant dialogue between the works. This certainly causes a critical attitude renewed by those who observe them. If our relationship with art is nonetheless intellectualized because the museum imposes, we can then question every work of art as the world's expression, as well as the reasons that come together in the same museum. However, human knowledge is broader than the collection of our museums, where the work of art seems to have only a contemplative function. In a context of global and relentless artistic exploration, the meeting of so many masterpieces and the absence of so many invites to meeting all of them within the human spirit through the imagination. Thus, the imaginary museum will aim to add as much as possible the incomplete collection imposed by the real museums. Through internet, numerous publications and many other possibilities, we have more significant works, images able to expand our memory in quantity superior to any of the works that the museum can own. The idea of dialogue between the works of this and many other last out also strengthened.

In this ambition, pop up also reviews itself as a tool that can expand the individual Imaginary museum, where everyone will be able to expand creativity and imagination towards knowledge.

\section{ABOUT EPHEMERALITY}

What is the phenomenon, which is the invariable, and what is the operating system/methodology used for its production? These are questions about the essence of the ephemeral, and, as such, questions which change according to the "will of the times." In this reflection on the ephemeral, it is considered that the object to assign the quality of the ephemeral is the event and, in this context, we identify the pop up as an extensible object of the intention of the subject. By its configuration it is possible to analyze the numerous possibilities of manifestation of the event, which through its emergency basis transform any seemingly stable scheme (everyday). Through a reversible process, the event returns to the individual and collective subject, aiming adjustment of the living organism which is the city.

The ephemerality is so precarious that has no tangible results. However, the intangibility is a human desire, a path to immortality. The event memory is worth more than the actual correlative fact, built, because the memory lingers even after the event itself.

The intention of the event requires the practice of the subject through action as an act or effect of acting of the subject through the object, the transformation of current events on a day-to-day.

For Heraclitus of Ephesus, nothing in the world is permanent except change and transformation. In subjectobject symbiosis the movement "to become" distinguishes the transformation of any state of affairs, from the moment in which the subject identifies, acting and performing any processing through the object.

Indeed, according to Silveira Dias and Loução (2015, pp. 17-18, author's translation), the "(...) objectivity is individual and given by each subject from the subjective relation to the object (...). This ratio is reflective and backward in accordance with the subject reflected permeability.", thus setting up the reversibility relationship, the reversed effect on the subject of the case.

Since always, and history remembers it, man goes through places and situations that change. As conditioned being, everything that comes in contact with it, it becomes a condition of its existence. "Men are conditioned beings because everything they come in contact with turns into immediately the condition of their existence." (Arendt, 1998, p. 09)

The permeability of the event through natural and urban places, fictitious and cyber as well as their vulnerability to situations that determine identity, articulation and exposure, make the subject a great protagonist of the event. "Your contingency or occurrence [event] becomes necessary, as a universal principle that will contribute to a new order." (Silveira Dias and Loução, 2015, p. 18, author's translation).

The quality of the ephemeral attaches itself to the object (the event) when located in a place and in a situational, indeterminate space, but given time. This temporal and spatial boundaries, distinguished the event as an object of ephemerality, and "Their invariable condition is produced in change, because nothing will remain the same after the event, even if the changes are not immediately evident. The variable condition of the event is the correlative effect to the cause of the event. "(idem, ibidem, p. 17) 
Indeed, the ephemeral results from the way that emerges without any spatial determination and interacts with the growing social and cultural change in the urban complexity, which gives it time determination from the moment it is identified. The ephemeral is distinguished by the emergence in uncertain territory, in its blurring of boundaries and structures that change, and appears to bridge, intervene, manifest and dream, in the territory of anyone, but in everyone time. According to Baudrillard (1991, p. 09), ephemeral can disguise, pretending not to have what it has and simulate, pretending to have that does not have and thus permits the disguise, the surprise, the fickleness, the audacity, the shrewdness, mobility and memory building.

\section{IN DIALECTIC OF INTERIOR AND EXTERIOR}

Since always, the sense of shelter is a primary need of man. The need for shelter to protect and be protected corresponds to the sense of belonging and home that is intrinsic to human behaviour as a place of reference and control of the situation. Bachelard (1978, p. 336, author's translation) states that "The short and the beyond dully repeat the dialectic of inside and outside: everything is drawn, even infinity. We want to fix the being, and to fix it, we transcend all situations to give one a situation of all situations"

According to Loução (2014, p. 173, author's translation), when it comes to the inside is the outside that is needed, that the architecture meets, building the shelter, the primary function which is home. The shelter that protects the interior and from where we left to return from abroad. The house as a place of truth, individual and authentic is repository of references and memories. Inside gives up the reunion, subjectivity, and then return to the interaction with the outside, objectivity. The interior is the first absence of necessity, already assured, when it comes to their relationship with the outside. Inside, "There is a sense in doing, creating scenarios, housing, while the architecture [because the outside] creates shelters, although it can enact them."

The space, as pre-existing reality, to be inhabited intangibly by the desire of the people, in the case of interior, deals with an architecture that could appoint convenient. Qualify as architecture of desire and not of necessity, adding to the essential functions of space moments of dreamed lives, is to approach the architecture of the set design, the staging of ways of being and, while it lasts, is to transform the common man in an exceptional identity.

The ephemeral does not treat the inside or the outside, but the time of things (objects) that have no place. The things that are inside or outside and that are both inside and outside. Ultimately, things can only display the surface that separates them, the door that is an entire cosmos of the ajar, according to Bachelard (1978, p. 342).

\section{IN EVERYDAY LIFE}

Whereas the architecture is the need and the interior of convenience, we can add to the definition of ephemeral the emergency feature. The ephemeral emergency in these uncertain future times, it may assist in the consolidation of the need and the stimulus of convenience. When speaking in this area of the ephemeral, we can say that it is the emergence in architecture, because the spaces appear and disappear, reveal themselves and hide up without warning. However, shares are recognized and identifiable because of its unpredictability and spontaneity in place: they are non-places.

Non-place means the space that is configured in relation to its function (transport, trade, leisure) and the relationship that people establish with this space. The overlap of these two relationships (because individuals travel, shop, have fun) not really get confused because the non-place mediates any relationship with themselves and others only indirectly related to their goals. They are places to the imagination, evoking the already configured for a required function and to evoke integration of a given situation. According to Augé (2012, p. 82, author's translation), it is the imaginary space that proposes new forms of interaction based on a "lonely contractuality". The non-place combines everyday functionality and the lost myth. Creates the image, produces the myth and at the same time make it work.

In the city, the ephemeral appears to address, such as infrastructure and essential service for a time, to intervene in post-disaster situations, but can also manifest ideals, protest absence of complex and extraordinary realities that are not accepted or ignored and abandoned. Also leads to dream, because of the registration circumstantial recognition, not calling for the evidence and so there will be something not controlled and intangible.

It is coated of political, social criticism and architecture. It may be representative of the minority, the difference, the absence or loneliness. It is routine interruption to the exceptionality of daily life, through reflection, memory and desire. Political, social, economic, natural, cultural, and catastrophic and war events are forms of action 
that alter the territory and the population. The city is reflected in the behaviour of the territory, creating and generating mechanisms of action which reflect the city life as a living organism in search of balance. Each individual builds his intimate territory, material and immaterial that reflects the contemporary complexity. It is the individualized fragmented territory where the need and the convenience make it essential to emergency in the transition to a more effective and sustainable life. Accentuate the dynamics of action, the mutability of the subject in flashback, flash forward and flash-sideway, identified in time. They are simultaneous actions and expandable objects as they are and as an extension of the subject in the territory, located on time, but developing a network in the complexity of the city. The nodes of this network (urbanity) identify themselves as places of action that promote the subject's behaviour for the construction of the object that is the city.

The ephemeral also witness and interprets the social desire. It reflects the experience in community, revealing itself as a regulator of the city, reflecting options, practices and concepts that define the time at present: that definitive present (instant) that successively changes and is in accordance with the individual and collective act of the subject.

Indeed, the ephemeral represents what happens at a given time so noticeable and regulates its life time and cycle. It is distinguished by the awareness of a pre-defined lifetime and because of their transience is interwoven dramatic sense, because of the intensity inherent in his "death" announced. By its pre-defined life cycle, it is permitted to trial (formal, material and sensory) due to programmatic irresponsibility. It legitimizes the ecstasy of the moment-present in the succession of time-infinite day-to-day. Hence, it becomes visible in the instant experience, and it is this short life that intensifies. It allows explore relationships between spaces, environments and people in a limited time experience through a complementary trusteeship, the coexistence of counterparts of the parties involved and the synergy of the universal. The ephemeral always requires new territories and visionary technologies, based on the strategy of provocation and consumption. It handles emotions and triggers sensations and develops the cognition of the subject, because, on the one hand, models the space / time, on the other, shapes the perception by experience exercised/enjoyed.

\section{THE NON-PLACE FOR CREATIVITY}

The design should serve the needs and desires of all of us. We are not satisfied with the fact of being merely "consumers" but we also want to be "creators". In this context, the design can be better understood if providing tools/models with which we can express our dreams and ambitions. We realized the wealth of creative experience when we observe social networks. We feel this emergency when we research on internet, on websites and personal blogs. It's amazing the creativity that comes from all parts and supplies, as we usually be given access to their homes, their work, to learning or experiences of reproductions. There are therefore many examples of creative behaviour of people and areas and diverse domains. The practical exercise of design certainly will enrich these various needs with creativity, and consequently experience through creative will find a better balance consumption pattern. The raw material for the experience in the design, in terms of ambition balance, may be underlying the experiences, work, leisure and individual learning. When we take advantage of our experience, we significantly change the process of design and the conduct of the design. This is no longer just for consumption, but expanding the learning from these experiences.

When we move away from the traditional areas of design that are developed on the materiality of the artefact (graphic, product, space, software, architecture), we approach the dominant immateriality of human experience, which is reflected in areas such as learning, creating, caring, being, working, playing and buying. The success of the design may be to evaluate it results in improving the individual and collective growth of the people and also in increasing the quality of their relationship with their contexts and engaging. That is, the evolution of design in terms of sustainability and coexistence of human experience, via the essential and not only the circumstantial.

The design learns to use your own creativity to stimulate the creativity of most people. The design is a tools generator and/or model on which we can all express our creativity through the creation of productive systems of intangible objects, such as "education," "health," "knowledge," or "decisions".

According to Flusser (2010, p. 13), design is the legitimate experience to bet in the world with intent and proper sense. Until very recently, industrial tools denied this possibility, because they granted to creators the power to determine the meaning and the expectations of others.

In this context, the ambition of the pop up is to be applied as a model to encourage and learn how to use creativity. The possibility of a place to stimulate creativity may involve the use of a non-place (pop up) that in its always amazing action can boost the affective state of the human being in relation to others and to the objects that surround it in a more sustainable ambition. 
The pop up as utopia (non-place) and way of thinking can look into ways of thinking about reality in order to achieve eventually a situation of social and urban perfection, based on your needs and concerns, using the fantasy, but without failing to take their feasibility. In practice, the utopian method, in a comprehensive manner, imagine everything in life made of interrelations and union of the parties, as an organic structure, with increasing organizational skills: the balance of which must be preserved to promote the development and transcendence (Mumford, 2007, p. 13).

In its revelation (pop up), we cannot understand the meaning of a part without understanding the meaning of the whole (the action in context), and we cannot understand the meaning of the whole without understanding the meaning of its constituent parts: object, place, time and movement, among others. We also cannot understand the meaning of an object until we can identify it in the context of interpretation as a whole (event) and cannot understand the full significance of this event until we understand the meanings of the parts that make up the object: shape, texture, colour, among others. The meaning of the pop up will depend on the context in which it could be proved, but this context is composed of concepts that gives meaning. In day-today, in relation to the world we live in, we perceive things without being properly conceptually seized as objects. Things are simply there and they aren't strange and distant, yet familiar and assimilated. According to Heidegger (Snodgrass \& Coyne, 1997, pp. 65-97) things are "made to our measure", in the circular movement of the parts that can be changed, verified, and added, being part of a horizon whose line drawn will be changing. And that horizon, continually expanding, returns to his roots and reinterprets them.

This circular motion in continuous reinterpretation defines the ephemerality of the parties in the eternity of the whole. As continuous evolution of the contribution of the parties, the ephemeral whole is constantly changing: the ephemeral elements of knowledge, which are modified by the eternal, reflecting the full knowledge and universal knowledge in permanent construction (eternal); the contribution of the different knowledge that modify it (ephemeral), which in its inconstancy of being give the possibilities, and in constant construction of the not to be, are distinguished by the uses of perpetual evolution of universal knowledge.

When we introduced the concept of need, one reaches the capital aspect of the biological value: the problem of the individual striving to maintain life and needs stemming from this effort. However, the reason attribute value, demands the recognition of the "(...) problem of maintenance of life and the needs which underlie it." (Damásio, 2010, p. 69, author's translation). Values are inevitably associated with needs, and tie them to life. The value we attach to social and cultural activities of the day-to-day has a link to the regulatory processes of life (homeostasis). The value being related to survival for humans is also related to the quality of that survival, expressed in the form of well-being.

Indeed, Damásio (2010, pp. 354-356) argues that human beings can associate individual biological needs to accumulated wisdom, generating the so-called biological revolution of "culture". Based on wisdom, we can decide and guide our behaviour according to the structure of cultural conventions and ethical values that build our biography and the world we live in. Build up the truth.

So that the truth can be processed, you need something to happen, because there is, the state of knowledge as it is, gives us just repetition. For a true affirm its newness, there must be something accruing to that, and what is left to chance. It is unpredictable and incalculable. It lies beyond what exists in the abstract sense and is defined as an event.

So, it is argued that the pop up is an abstract concept of event, aiming to reduce this concept to the key to understanding the circumstantial: a model that brings out the material world chaos reality constituted by the formal world. The support and promotion of pop up as an organism in constant motion and adaptable to the place, seeks balance and develop the capacity of the vital regulation of being.

If humans react emotionally to the event (pop up), its strategic definition will contribute to the social and cultural homeostasis, according to Damásio (2010, p. 50, author's translation), "(...) especially if, in addition to knowing who we are presently, we should worry about what we may be."

Promoting behaviours we promote accountability. 

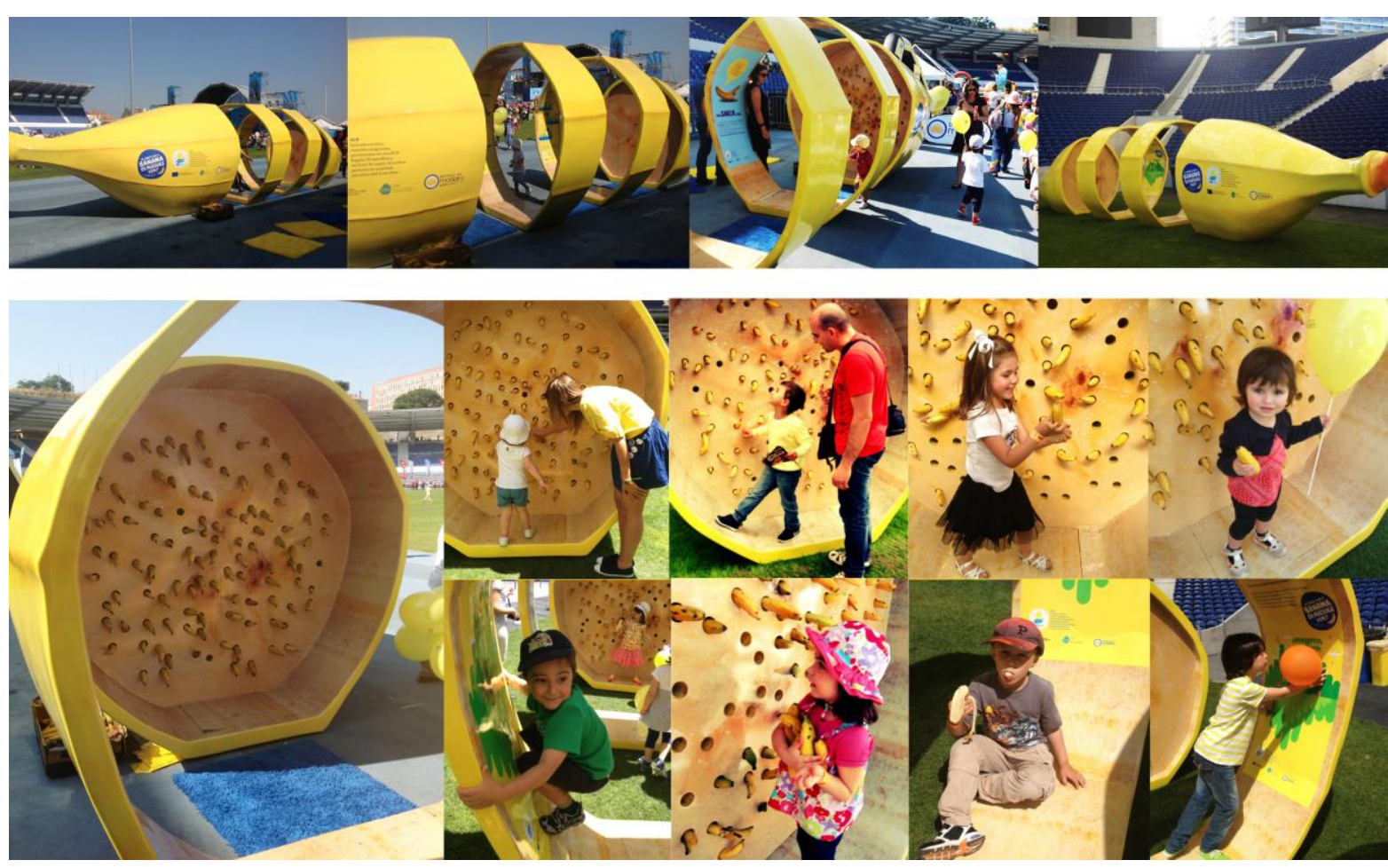

Fig. 1. Ephemeral installation in Panda Festival of the brand "Madeira's Banana" in order to explain children the composition of a banana (author's work, June 2014)

\section{ACKNOWLEDGEMENT}

This research was financially supported by the Research Centre for Architecture, Urbanism and Design (CIAUD) at the Faculty of Architecture, University of Lisbon (FA/ULisboa), R\&D Unit $n^{\circ} 4008$ and the Funding Agency for Science, Research and Technology (FCT), Portugal.

\section{REFERENCE LIST}

Arendt, H. (1998). The Human Condition. Chicago: University of Chicago Press.

Auge, M. (2007). Não-Lugares: IntroduçÃo A Uma Antropologia Da Supermodernidade. Campinas: Papirus. Bachelard, G. (1978). A Poética do Espaço. São Paulo: Abril Cultural (1).

Baudrillard, J., \& Pereira, M. J. C. (1991). Simulacros e Simulação. Lisboa: Relógio dpÁgua. (1);

Damásio, A. (2010). O Livro da Consciência. A Construção do Cérebro Consciente. Temas e Debates (1).

Flusser, V. (2010). Uma Filosofia do Design. A Forma das Coisas. Lisboa: Relógio D'Água (1).

Goldberg, R. (2012). A Arte da Performance. Do Futurismo ao Presente. Orfeu Negro.(2).

Locker, P. (2011). Exhibition Design. Lausanne, Switzerland: AVA Pub. (1).

Loução, D. (2014). A Arquitetura como desejo de existir, Arquiteturas do Mar, da Terra e do Ar, 1(1).

Mesher, L. (2010). Retail Design. Lausanne, Switzerland: AVA Pub. (1).

Malraux, A. (2014). O Museu Imaginário. Edições 70 (1).

Mumford, L. (2007). História das Utopias. Antígona (1).

Silveira Dias, J. and Loução, D. (2015). "Anatomia de um Evento: Reflexão sobre a Causalidade. Proporção, des-Harmonias e Identidades, (1).

Snodgrass, Adrian and Richard Coyne (1997). "Is Designing Hermeneutical? Architectural Theory Review, Journal of the Department of Architecture, The University of Sydney, Vol. 1, No. 1, pp 65-97 (1). 